\title{
Pharmacology and Pharmacy Research in India: A Scientometrics Study
}

\author{
Chaman Sab M*, Dharani Kumar P, B. S. Biradar \\ Department of Library Information Science, Kuvempu University, Shankaraghatta, Karnataka, INDIA.
}

\section{Received: 03 May 2019; \\ Accepted: 19 June 2019 \\ *Correspondence to: \\ Dr. Chaman Sab M,}

Research Scholar, Department of Library Information Science, Kuvempu University, Shankaraghatta, Shimoga, Karnataka-577451,

INDIA.

Email:chamansabm@gmail.com

Copyright: (c) the author(s),publisher and licensee Indian Academy of Pharmacists. This is an open-access article distributed under the terms of the Creative Commons Attribution Non-Commercial License, which permits unrestricted non-commercial use, distribution, and reproduction in any medium, provided the original work is properly cited.

\begin{abstract}
Analyses the Indian publications output in Pharmacology and Pharmacy during 2004-18 on several parameters including contribution and citation impact of most productive countries, India's overall contribution, its growth pattern, citation impact, the share of international collaboration, identification of significant participating countries in India's international collaboration, most productivity and impact of leading Indian institutions and authors. The Web of Science Citation Database has been used to retrieve the data for 15 years (2004-18) by searching the keywords "Pharmacology and Pharmacy" in combined Title, Abstract and Keywords field. The Indian publications output in Pharmacology and Pharmacy research consisted of 37,734 papers during 2004-18, which increased from 1045 papers in 2005 to 3,042 papers in 2014, which decreased from 2,898 during 2015 and 1,817 during to 2018. The share of Indian overall Pharmacology and Pharmacy research was $11.56 \%$ during $2003-12$, which increased from $10.43 \%$ during $2003-07$ to $12.18 \%$ during 2008-12. Indian research out put on Pharmacology and Pharmacy is quite low in the global context as reflected from its publication output per thousand publication (0.001) and its world publication share (3.28\%) during $2004-2018$. Also, the impact and quality of Indian research is low compared to select development and developing countries.
\end{abstract}

Key words: Pharmacology, Pharmacy, India, Research output, Scientometric analysis.

\section{INTRODUCTION}

Pharmacology is one of the main disciplines under biomedical science and the pharmaceutical industry. There are many disciplines within the biomedical sciences. Pharmacy is related to health sciences. It is the profession responsible for the preparation, dispensing and appropriate use of medication and which provides services to achieve optimal therapeutic outcomes. A pharmacist's job is to prepare, mix, compound or dispense drugs and medicines, ointments, powder, pills, tablets and injections on the prescription of a medical practitioner, dentist or veterinarian. In detail, they are concerned with production of pharmaceutical products, development of the methods or processes of production and quality control. Those in research concern themselves with synthesis of new drugs (what is commonly referred to as molecules), new processes, clinical testing of the effects of such drugs on animals and humans and obtaining the required license from the drug control authorities. A pharmacist is required to explain the mode and precautions regarding the use of medicines dispensed in a hospital pharmacy, prepare special formulations normally not available in the market, assist the physician in rendering necessary information about various drugs, their contra-indications, incompatibility etc. ${ }^{[1]}$

\section{Review of Literature}

A few evaluative studies have been carried out in the past on contribution and impact of pharmacological Research measured in terms of publications output. Ahila and Nagarajan. ${ }^{[2]}$ Analysis 22,065 global publications in pharmaceutical research, deriving publication data from Web of Science database during 1999-2010 (12 years). Its analysis the global publication growth, share and rank of top 15 most productive countries, authorship pattern, identic action of high productive institutions and journals. Har Kaur and Gupta ${ }^{[3]}$ examines India's performance in pharmacology, using Scopus database during 1998-2007, based on several parameters, such as global publication shares and rank of top 15 most productive countries, India's publication growth, citation impact and international collaborative share, institutional profile of select leading institutions, pattern of communication and contribution and impact of most productive authors, etc. Gupta and Har Kaur et al. ${ }^{[4]}$ analysis ranking of most productive Indian institutions in pharmacology for their research output during 2000-2009. Their output is judged on the basis of few quantitative and qualitative indicators.

Few Scientometric studies have been published in the area. Reddy and Mahesh Kumar $^{[5]}$ provided a Scientometrics analysis of world papers published by 57 countries in 10 major sub - specialities appearing in three leading international journals during the ten-year period. Dotson et al. ${ }^{[6]}$ analysed changes in the authorship and characteristics of articles in pharmacy journals during the 20-year period. In the field of Bibliometrics of country output in pharmacology only a few studies have been carried out on India. Gupta, Ritu and Kumar ${ }^{[7]}$ Chaman, Kumar and Biradar; ${ }^{[8,9]}$ Li, G et al. ${ }^{[10]}$ analysed the research output performance on Pharmacology and Biomedicine. A total of 22,065 research articles published in Web of Science were analysed to find the performance of scientists from all over the world in terms of growth during the period 1999-2010 (12 years). Annual growth rate, global publication shares and rank among 15 countries of the world, authorship pattern, high productive Institutions, Journals, etc were discussed. Biradar and Vijayalaxmi ${ }^{[11]}$ Kannappanavar B.U, Chidanand Swamy and Vijayakumar $\mathrm{M}^{[12]}$ Bagalkoti and Hosamani ${ }^{[13]}$ highlighted the authorship trend and collaborative research in chemistry in India during 1996-2000. The study found that team research is preferred in the field of chemistry rather than solo research. The degree of collaboration is calculated and found total 0.76 . The degree of collaboration varies from year to year and is found to be 0.72 to 0.83 . Average number of authors per paper has increased from 7.52 to 8.39. Ann Barrett, Melissa Helwig and Karen Neves ${ }^{[14]}$ described the literature of hospital pharmacy and identifies the journals most commonly 
cited by authors in the field, the publication types most frequently cited, the age of citations and the indexing access to core journals. The study also looks at differing citation practices between journals with a wide audience compared to a national journal with a focus on regional issues and trends in the field and found that, Three-quarters of all cited items were published within the last 10 years $(71 \%)$ and journal articles were the most heavily cited publication type $(87 \%)$.

\section{OBJECTIVES}

The paper studies the performance of top 15 high productivity countries, Indian top 15 high productive institutions in pharmaceutical science by using quantitative and qualitative indicators to understand their comparative strength and weakness. The contribution of various sub - fields in Pharmacology and Pharmacy research. Indian research output, its growth and global publications share and impact, the pattern of international collaboration and major collaborative partners. The study also examines how different models of institutional funding influence performance in pharmaceutical research in India. The characteristics of the most prolific authors and high cited papers.

\section{MATERIALS AND METHODS}

This study was undertaken based on the publication data from India and also identifies the top 15 most productive countries in the field of pharmaceutical research. Data for the present study were retrieved from the Clarivate Web of Science (WoS) international multidisciplinary bibliographical database [http://www. webofknowledge.com/] for the last ten years (2004-2018). The search strategy string used to retrieve the main data on research output, institutions, authors and major journals of India is as follows:

\section{DATA ANALYSIS AND RESULTS}

India's publications output during 2004 - 2018 consists of 37808 papers, with an 497428 total citations and average papers per year. Highest publication output in the year of 2011 to 2017 and lowest publications founded in the year of 20041061 publications. Table 1
India's Publications output in Pharmacology and Pharmacy research

\section{Global publications share}

The global publications share of the topmost productive countries in Pharmacology and Pharmacy research various from $2.55 \%$ to $38.61 \%$ share of publications from 2004 - 2018. The USA tops the list, with share $38.61 \%$ during $2004-2018$ and in the year of 2004 to 2008 share of publications are very high $42.82 \%$ share). The Malaysia share of publications at second position with $7.66 \%$ share, England (7.06\% Share), Australia (6.95\% share), Germany (5.52\% share), China (5.18\% Share), Switzerland (4.23\% Share). The lowest increase in their publications share is shown by Singapore (1.95\%), followed by Belgium (2.33\%) share of publications, Among the top 15 most

\begin{tabular}{|c|c|c|c|c|c|}
\hline SN & Year & TP & TC & ACP & h Index \\
\hline 1 & 2004 & 1061 & 34706 & 34.16 & 84 \\
\hline 2 & 2005 & 1045 & 34748 & 33.25 & 84 \\
\hline 3 & 2006 & 1345 & 41866 & 31.3 & 85 \\
\hline 4 & 2007 & 1606 & 43121 & 26.85 & 91 \\
\hline 5 & 2008 & 2850 & 46411 & 16.28 & 82 \\
\hline 6 & 2009 & 2621 & 51729 & 19.74 & 84 \\
\hline 7 & 2010 & 2831 & 50649 & 17.89 & 81 \\
\hline 8 & 2011 & 3023 & 43901 & 14.52 & 68 \\
\hline 9 & 2012 & 3042 & 41310 & 13.58 & 62 \\
\hline 10 & 2013 & 3894 & 34890 & 8.96 & 60 \\
\hline 11 & 2014 & 3402 & 31284 & 9.2 & 51 \\
\hline 12 & 2015 & 2898 & 21245 & 7.33 & 40 \\
\hline 13 & 2016 & 3198 & 14949 & 4.67 & 31 \\
\hline 14 & 2017 & 3146 & 6081 & 1.93 & 19 \\
\hline \multirow[t]{2}{*}{15} & 2018 & 1846 & 538 & 0.3 & 5 \\
\hline & & 37808 & 497428 & & \\
\hline
\end{tabular}

$\mathrm{TP}=$ Total Publications $; \mathrm{TC}=$ Total Citations; $\mathrm{ACCP}=$ Average citations per Papers.

\begin{tabular}{|c|c|c|c|c|c|c|c|}
\hline \multirow[t]{2}{*}{ Country } & \multicolumn{4}{|c|}{ Number of Papers } & \multicolumn{3}{|c|}{ Share of Papers } \\
\hline & $2004-2008$ & $2009-2013$ & $2014-2018$ & $2004-2018$ & $2004-2008$ & $2009-2013$ & $2014-2018$ \\
\hline USA & 436 & 869 & 1224 & 234267 & 42.83 & 43 & 38.61 \\
\hline Germany & 80 & 113 & 175 & 77940 & 7.9 & 5.63 & 5.52 \\
\hline England & 77 & 120 & 224 & 63796 & 7.56 & 5.94 & 7.06 \\
\hline Japan & 69 & - & - & 51574 & 6.77 & - & - \\
\hline Italy & 45 & 93 & 155 & 93441 & 4.42 & 4.6 & 4.89 \\
\hline France & 44 & 73 & 121 & 54423 & 4.32 & 3.61 & 3.81 \\
\hline Canada & 43 & 85 & 121 & 38791 & 4.22 & 4.2 & 3.81 \\
\hline South Korea & 39 & 97 & 173 & 27145 & 3.83 & 4.8 & 5.45 \\
\hline Belgium & 37 & 70 & 74 & 37734 & 3.63 & 3.46 & 2.33 \\
\hline China & 32 & 65 & 164 & 37518 & 3.14 & 3.21 & 5.18 \\
\hline Australia & 27 & 80 & 219 & 29723 & 2.65 & 3.95 & 6.95 \\
\hline Singapore & 25 & 44 & 62 & 20470 & 2.45 & 2.17 & 1.95 \\
\hline Malaysia & 22 & 185 & 243 & 19526 & 2.16 & 9.15 & 7.66 \\
\hline Switzerland & 21 & 72 & 134 & 21799 & 2.06 & 3.56 & 4.23 \\
\hline \multirow[t]{2}{*}{ Taiwan } & 21 & 55 & 81 & 16285 & 2.06 & 2.72 & 2.55 \\
\hline & 1018 & 2021 & 3170 & & 100.00 & 100.00 & 100.00 \\
\hline
\end{tabular}


productive countries, the publications rank has increased in England (from $3^{\text {rd }}$ to $2^{\text {nd }}$ Rank), Malaysia (from $13^{\text {th }}$ to $3^{\text {rd }}$ Rank) and Australia (from 11th to $5^{\text {th }}$ Rank), Switzerland (from $14^{\text {th }}$ to $4^{\text {th }}$ Rank). (Table 2).

India's contribution, citation impact and international collaboration

India published $37.73 \%$ share of list of its total output on Pharmacology and pharmacy research. India's international collaboration was largest with USA 2531 papers (44117 citations) with 17043 average citations per papers, followed by South Arebia 654 papers $(7165$ citations par papers, Malaysia 450 papers with 5008 citations per papers, England 422 papers with 6920 citations, (16.4\% average citations per citations), Germany 369 papers with 6202 citations $(16.18 \%$ average citations per papers, Australia published 326 papers with 4759 citations and $14.6 \%$ average citations per papers. (Table 3 ).

\begin{tabular}{|c|c|c|c|c|c|}
\hline SN & Country & TP & $\mathrm{CP}$ & ACP & h Index \\
\hline 1 & USA & 2531 & 44117 & 17043 & 85 \\
\hline 2 & South Arabia & 654 & 7165 & 10.96 & 36 \\
\hline 3 & Malaysia & 450 & 5008 & 11.13 & 29 \\
\hline 4 & England & 422 & 6920 & 16.4 & 42 \\
\hline 5 & Germany & 369 & 6202 & 16.18 & 39 \\
\hline 6 & Australia & 326 & 4759 & 14.6 & 37 \\
\hline 7 & South Korea & 309 & 4271 & 13.82 & 32 \\
\hline 8 & Italy & 293 & 5831 & 19.92 & 36 \\
\hline 9 & Peoples of China & 265 & 4513 & 17.03 & 34 \\
\hline 10 & Japan & 264 & 3830 & 14.51 & 30 \\
\hline 11 & Canada & 249 & 3861 & 51.51 & 34 \\
\hline 12 & France & 238 & 3808 & 16 & 33 \\
\hline 13 & Switzerland & 224 & 2482 & 11.08 & 25 \\
\hline 14 & South Africa & 223 & 2264 & 10.15 & 25 \\
\hline 15 & Belgium & 182 & 2806 & 15.42 & 29 \\
\hline
\end{tabular}

\begin{tabular}{|c|c|c|c|c|c|}
\hline SN & Subjects & TP & TC & ACP & \%TP \\
\hline 1 & Pharmacology pharmacy & 27454 & NA & NA & NA \\
\hline 2 & Chemistry medicinal & 14542 & NA & NA & NA \\
\hline 3 & Biochemistry molecular biology & 3229 & 51022 & 15.8 & 83 \\
\hline 4 & Chemistry organic & 2320 & 51069 & 22.01 & 84 \\
\hline 5 & Plant sciences & 2300 & 34573 & 15.03 & 71 \\
\hline 6 & Toxicology & 2115 & 32597 & 15.41 & 66 \\
\hline 7 & Chemistry multidisciplinary & 1660 & 33783 & 20.35 & 76 \\
\hline 8 & $\begin{array}{l}\text { Integrative complementary } \\
\text { medicine }\end{array}$ & 1552 & 29064 & 19.1 & 70 \\
\hline 9 & Medicine research experimental & 1345 & 17914 & 13.32 & 59 \\
\hline 10 & Chemistry applied & 1175 & 8853 & 7.53 & 34 \\
\hline 11 & Chemistry analytical & 984 & 11810 & 12 & 44 \\
\hline 12 & Neurosciences & 848 & 12642 & 14.91 & 51 \\
\hline 13 & Biochemical research methods & 730 & 5021 & 6.88 & 28 \\
\hline 14 & Microbiology & 699 & 14738 & 21.08 & 56 \\
\hline \multirow[t]{2}{*}{15} & Education scientific disciplines & 607 & 1112 & 1.67 & 13 \\
\hline & & 61560 & 304198 & & \\
\hline
\end{tabular}

$N A=$ Not available in web of science database
Pharmacology and Pharmacy research output by different subject

India's publication output in Pharmacology and Pharmacy research during $2004-2018$ has been published in context of 715 subjects (as reflected in database classification-based journal), with highest publications output coming from Pharmacology and Pharmacy (27454 papers and more than 10, 0000 citations), followed by Chemistry and Medicinal (14542 papers and more than 10,000 citations), Biochemistry molecular biology (3229 papers with 51022 citations and $83 \mathrm{~h}$ index), Chemistry organic (2320 papers with 51022 citations and 22.01 average citations per papers and $84 \% \mathrm{~h}$ index), Plant sciences (2300 papers with 34573 citations were collected is highest and average citations per paper 15.05 and $71 \% \mathrm{TP}$ ), Toxicology (2115 papers with 32597 citations, 15.41 average citations per papers and $66 \mathrm{~h}$ index ), lowest publications found from the subject of Microbiology (699 papers with 14738 citations, highest average citations per paper found $21.08 \%$ and $56 \mathrm{~h}$ index), followed by Education scientific disciplines (607 papers with 1112 citations, $1.67 \%$ average citations per papers and $13 \mathrm{~h}$ index). On analysing the quality and impact of Pharmacology and Pharmacy research output under different subjects, it was found that Chemistry Organic secured the highest impact (22.01\% citations per paper), etc (Table 4).

Research profile of most productive Indian Institutions in Pharmacology and Pharmacy research in India

Top 15 most productive Indian Institutions involved in Pharmacology and Pharmacy research have published 17131 and 276506 citations. The publications profile of those 15 Indian institutions along with their research output, citations received and $\mathrm{h}-$ index values are presented in the table (Table 5). India's publication output in Pharmacology and Pharmacy research during 2004-2018 has been published in context of 715 subjects (as reflected in database classification-based journal), with highest publications output coming from Pharmacology and Pharmacy (27454 papers and more than 10, 0000 citations), followed by Chemistry and Medicinal (14542 papers and more than 10,000 citations), Biochemistry molecular biology (3229 papers with 51022 citations and $83 \mathrm{~h}$ index), Chemistry organic (2320 papers with 51022 citations and 22.01 average citations per papers and $84 \% \mathrm{~h}$ index), Plant sciences (2300 papers with 34573 citations were collected is highest and average citations per paper 15.05 and $71 \% \mathrm{TP}$ ), Toxicology (2115 papers with 32597 citations, 15.41 average citations per papers and $66 \mathrm{~h}$ index ), lowest publications found from the subject of Microbiology (699 papers with 14738 citations, highest average citations per paper found $21.08 \%$ and $56 \mathrm{~h}$ index), followed by Education scientific disciplines (607 papers with 1112 citations, $1.67 \%$ average citations per papers and $13 \mathrm{~h}$ index). On analysing the quality and impact of Pharmacology and Pharmacy research output under different subjects, it was found that Chemistry Organic secured the highest impact (22.01\% citations per paper), etc. (Table 5).

\section{Contributions and impact of most productive Indian} authors in Pharmacology and Pharmacy research

Fifteen authors have been identified as most productive, who have published 5 and above papers in Pharmacology and Pharmacy research. The publications profile of these 15 authors along with their research output, citations received and $\mathrm{h}$ index values are presented in (Table 6). These 15 authors involved in Pharmacology and Pharmacy research together have contributed 96 papers in Pharmacology and Pharmacy research during 2004 - 2018. They are Swarnalata Sarat published 9 papers with 20 citations, $2.22 \%$ average citations per paper and $2 \mathrm{~h}$ - index, followed by Anand Panchakshari Gadad published 8 papers with 1 citations $0.13 \%$ average citations per papers, Highest citations 


\begin{tabular}{|c|c|c|c|c|c|}
\hline SN & Address & TP & CP & ACP & h Index \\
\hline 1 & Council of scientific industrial research CSIR India & 4916 & 78409 & 15.95 & 88 \\
\hline 2 & CSIR central drug research Institute & 1361 & 21388 & 15.71 & 58 \\
\hline 3 & National institute of pharmaceutical education research NIPPER & 1289 & 24295 & 18.85 & 69 \\
\hline 4 & Jamia Hamdard University & 1196 & 19243 & 16.09 & 60 \\
\hline 5 & Indian institute of Technology system IIT system & 1193 & 19154 & 16.06 & 59 \\
\hline 6 & Panjab University & 1054 & 19275 & 18.29 & 61 \\
\hline 7 & Indian institute of Chemical Technology & 1025 & 17843 & 17.41 & 53 \\
\hline 8 & University of Delhi & 714 & 12566 & 17.6 & 51 \\
\hline 9 & Jadavpur University & 698 & 11782 & 16.88 & 45 \\
\hline 10 & Manipal University & 682 & 5994 & 8.79 & 40 \\
\hline 11 & Banaras Hindu university & 667 & 9168 & 13.75 & 43 \\
\hline 12 & Annamalai University & 623 & 11586 & 18.6 & 48 \\
\hline 13 & Birla Institute of technology science & 604 & 9342 & 15.47 & 45 \\
\hline 14 & Defence research development Organization DRDO & 564 & 8671 & 15.37 & 46 \\
\hline \multirow[t]{2}{*}{15} & All India Institute of Medical sciences & 545 & 7790 & 14.29 & 44 \\
\hline & & 17131 & 276506 & & \\
\hline
\end{tabular}

\section{Table 6: Productivity and citations impact of India's top fifteen authors in Pharmacology and Pharmacy research $2004-2018$.}

\begin{tabular}{|l|l|l|l|l|l|}
\hline SN & Authors & TP & TC & ACP & H - Index \\
\hline 1 & Swarnalata Sarat & 9 & 20 & 2.22 & 2 \\
\hline 2 & Anand Panchakshari Gadad & 8 & 1 & 0.13 & 1 \\
\hline 3 & Yadav. AV & 8 & 46 & 5.75 & 4 \\
\hline 4 & Swamy P. V & 7 & 18 & 2.57 & 3 \\
\hline 5 & Pravin Panchakshri Chaudari & 6 & 24 & 4 & 3 \\
\hline 6 & Panchaksri Mallappa Dandagi & 6 & 1 & 0.17 & 1 \\
\hline 7 & Shivaji Gada & 6 & 10 & 1.67 & 2 \\
\hline 8 & Kulkarani & 6 & 9 & 1.5 & 1 \\
\hline 9 & Shailendar Kumar & 6 & 27 & 4.5 & 3 \\
\hline 10 & Jayadevappa Patil & 6 & 5 & 0.83 & 2 \\
\hline 11 & Monica Rao & 6 & 5 & 2 & 3 \\
\hline 12 & Mahaveer Singh & 6 & 12 & 4.67 & 3 \\
\hline 13 & Ahamed Sufiyan & 6 & 28 & 1.6 & 2 \\
\hline 14 & Satish Bhise & 5 & 8 & 0.6 & 1 \\
\hline 15 & Abhishek Gupta & 5 & 3 & 1 & 1 \\
\hline
\end{tabular}

score from Yadav A.V published 46 (8 papers) with 5.75\% average citations per papers $4 \mathrm{~h}$ - index, Swamy P.V. published 24 citations ( 7 papers) with $2.57 \%$ average citations per papers $3 \mathrm{~h}$ index, Pavin Panchakshri Chaudari published 6 papers with 24 citations ( $4 \%$ average citations per papers), 3 h index, Panchaksri Mallappa Dandagi published 6 papers with 1 citations with $0.17 \%$ average citations per paper, $1 \mathrm{~h}$ index, Shivaji Gada published 6 papers (10 citations) with $1.67 \%$ average citations per paper with $2 \mathrm{~h}$-Index, Kulkarni published 6 papers ( 9 citations) with $1.5 \%$ average citations per papers, $1 \mathrm{~h}$ - index, Shailendar Kumar published 6 papers with 27 citations ( $4.5 \%$ average citations per papers, $3 \mathrm{~h}-$ index and etc. (Table 6$)$.

\section{DISCUSSION}

Indian research out put on Pharmacology and Pharmacy is quite low in the global context as reflected from its publication output per thousand publication (0.001) and its world publication share (3.28\%) during $2004-$ 2018. Also, the impact and quality of Indian research is low compared to select development and developing countries. A detail scientometric analysis of Pharmacology and Pharmacy of India and its comparison with other countries is very important to obtain a clear picture and to take necessary measures to upgrade the research performance. It is important to evaluate the research performance of major Pharmacology and Pharmacy research institutes of the country and to compare their performance among themselves and similar institutes of other countries. The growth in literature has become a major concern for the scientists, scholars and library professional as they try to keep themselves abreast with new advances in their subject and information professionals try to organize this knowledge.

\section{CONCLUSION}

India is far behind USA, Malaysia, Arabia, England, Germany, Australia and South Korea in terms of publication output, citation quality and share of international papers in Pharmacology and Pharmacy. There is an urgent need for substantial increase in research and development investments, both at institutional level as well as in terms of extramural funding from different scientific agencies. Academic institutions should take steps to crate interest in research in Pharmacology and Pharmacy among graduate and postgraduate students and also among young pharmacists and scientist. Such efforts should include specialised training programmes with support from funding agencies. In addition, existing training programmes at the institutional level need to be strengthened, besides building new more comprehensive training programmes to develop manpower needs. There should be a substantial 


\section{Chaman, et al.: Scientometrics Study on Pharmacology and Pharmacy Research}

increase in international collaboration to increase the output and also improve the quality of research. In addition, there should be more collaboration among the Indian Institutions.

\section{ACKNOWLEDGEMENT}

The authors thanks to the Head of the Department of Library and Information Science, Dharwad and Dr. Vitthal Bagalkoti, Library and Information Officer, CMR University, Bangalore for providing necessary facilities and resources for completing this research article. This research no grant from any funding agencies.

\section{CONFLICT OF INTEREST}

The authors declare no conflict of interest.

\section{ABBREVIATIONS}

None.

\section{REFERENCES}

1. Hugar J, Chaman SM. Research Publication Trend in Pharmaceutical Sciences: A Bibliometric analysis during 2013-2017. International Journal of Library and Information Studies. 2018;8(2):115-22.

2. Ahila M, Nagarajan M. Research Publication Trend on Pharmacology Research. Library Progress. 2011;31(1):79-89.

3. Har K, Gupta B. Indian Contribution in Pharmacology, Toxicology and Pharmaceutics during 1998-2007: A Scientometric Analysis. Collnet Journal of Scientometrics and Information Management. 2009;3(1):1-9.

4. Gupta BM, et al. Acute Pancreatitis Research in India: A Scientometric Assessment of Publications during 2007-16. Kenkyu Journal of Gastroenterology. 2018;1(3):1-13

5. Reddy PM, et al. ANA Scientometric analysis for identifying major specialties for Pharmacological research and geographical contributions. Indian Journal of Pharmacology. 2016;38(2):137-9.

6. Dostan B, et al. Authorship and characteristics of articles in pharmacy journals: Changes over 20 year's interval, Annals of Pharmacy journals: changes over 20-year interval. Annuals of Pharmacotherapy. 2011;45(3):357-63.

7. Ritu G, et al. High Productivity Pharmaceutical Organisations in India: A Study of their performance during 2008-2012. Journal of Youg Pharmacists. 2014;6(2):4-13. doi:10.5530/jyp.2014.2.2

8. Chaman M, et al. Mapping of Indian biomedicine research: a Scientometric analysis of research output during 2012-2016. International Journal of Current Advanced Research. 2017;6(7):4688-91.

9. Chaman M, et al. Scientometric Profile of Dentistry, Oral Surgery and Medicine Research in India with reference to Web of Science (WoS) citation database during 2007 -2016. International Journal of Research in Library Science. $2017 ; 3(2): 102-12$

10. Li G, et al. Scientific publications in pharmacology and pharmacy journals from Chinese authors in various parts of North Asia: a 10 year's survey of literature. Journal of International Medical Research. 2010;38(3):750-9.

11. Biradar BS, Vijayalaxmi T. Pattern of information use by Indian neurological scientists-A bibliometric study. 1997.

12. Kannappanavar BU, et al. Publishing Trends of Indian Chemical Scientists. Annals of Library and Information Studies. 2004;51(1):39-41.

13. Bagalkoti VT, Hosamani SC. Mapping of the Indian Research Productivity of Biochemistry and Molecular Biology: A Scientometric Analysis. Journal of Advances in Library and Information Science. 2014;3(3):249-56.

14. Barrett $A$, et al. Mapping the literature of hospital pharmacy. Journal of Medical Library Association. 2016;104(2):118.

Cite this article as: Sab MC, Kumar PD, Biradar BS. Pharmacology and Pharmacy Research in India: A Scientometric Study. J Pharm Pract Community Med. 2019;5(2):38-42. 